\title{
PENERAPAN METODE EDUTAINMENT DAN STORY TELLING PADA GURU-GURU TAMAN PENDIDIKAN QURAN (TPQ) NATIQUL QURAN
}

\author{
Adi Permana, Hilda Hilaliyah, Siti Jubei
}

\author{
Pendidikan Bahasa Indonesia, \\ Fakultas Bahasa dan Seni, Universitas Indraprasta PGRI \\ Jl. Nangka no.58c, Tanjung Barat, Jagakarsa, Jakarta, Indonesia
}

\begin{abstract}
Abstrak
Metode Edutainment merupakan sebuah metode atau model pembelajaran yang digunakan dalam pendidikan yang dipadukan atau dikombinasikan dengan hiburan sehingga anak/peserta didik tidak merasa jenuh maupun bosan dalam mempelajari apa yang diajarkan oleh guru/pengajar. Bercerita (storytelling) adalah cara bertutur dan menyampaikan cerita atau memberikan penjelasan secara lisan. Bercerita juga merupakan cara untuk menyampaikan nilai-nilai yang berlaku di masyarakat. Seorang guru hendaklah mampu menjadi seorang pendongeng yang baik yang akan menjadikan cerita sebagai kegiatan bermain yang menarik dan dapat menjadikan pengalaman yang unik bagi anak. Berdasarkan hasil kegiatan pengabdian kepada masyarakat yang telah dilakukan, tampak antusias para peserta, yaitu guru-guru TPQ, terhadap tahapan yang dilalui. Pada saat penyampaian materi, para peserta aktif bertanya terkait dengan materi yang disampaikan. Selain itu, para guru TPQ mulai menerapkan metode edutainment dan storytelling dalam menyampaikan materi. Hal ini menjadi indikator yang positif bahwasanya kegiatan seperti ini sangatlah dibutuhkan untuk menambah pengetahuan dan meningkatkan kemampuan berbicara para guru pada saat proses belajar-mengajar di kelas.
\end{abstract}

Kata kunci: edutainment, storytelling, guru-guru TPQ.

\begin{abstract}
Edutainment method is a method or learning model used in education that is integrated or combined with entertainment so that children / students do not feel bored or bored in learning what is taught by the teacher / teacher. Storytelling is a way of speaking and telling stories or giving verbal explanations. Storytelling is also a way to convey the values that apply in society. A teacher should be able to be a good storyteller who will make the story an interesting playing activity and can make the experience unique to the child. Based on the results of the community service activities that had been carried out, it seemed enthusiastic about the participants, namely TPQ teachers, on the stages they were going through. At the time of delivery of the material, the active participants asked questions related to the material presented. In addition, TPQ teachers began applying the edutainment and storytelling methods in delivering material. This is a positive indicator that activities like this are needed to increase knowledge and improve the speaking capacity of teachers during the teaching and learning process in the classroom.
\end{abstract}

Keywords: edutainment, storytelling, TPQ teachers.

Correspondence author: Adi Permana, adipermana8579@gmail.com, Depok, Indonesia

This work is licensed under a $C C-B Y-N C$ 


\section{PENDAHULUAN}

Taman Kanak-Kanak dan Taman Pendidikan Quran termasuk ke dalam kategori lembaga pendidikan prasekolah atau Pendidikan Anak Usia Dini (PAUD). Pendidikan Anak Usia Dini memegang peranan yang sangat penting terhadap tumbuh-kembang anak. Oleh karena itu, para guru yang mengajar di lembaga-lembaga pendidikan tingkat usia dini tersebut seyogianya mempunyai kompetensi dan keterampilan yang memadai. Guru yang tidak sesuai dengan kompetensi atau kualifikasinya akan mengakibatkan dampak yang tidak baik terhadap perkembangan pendidikan anak usia dini.

Pembelajaran di tingkat pendidikan usia dini, dalam hal ini TK dan TPQ memiliki karakteristik yang berbeda dengan jenjang pendidikan setelahnya. Bila guru tidak mempunyai kompetensi di bidang pendidikan anak usia dini, tidak menutup kemungkinan akan terjadi perbedaan pemahaman dalam pelaksanaan pembelajaran dan dampaknya justru pada perkembangan anak. Salah satu kompetensi yang harus dimiliki oleh guru pendidikan anak usia dini adalah keterampilan berbicara.

Keterampilan berbicara adalah kemampuan mengungkapkan ide dan gagasan secara lisan. Keterampilan ini dimiliki seseorang secara alami atau pun dengan menggunakan latihan khusus. Beberapa metode dapat kita lakukan untuk meningkatkan kemampuan berbicara kita, yaitu dengan metode edutainment dan metode bercerita (storytelling).

Edutainment merupakan sebuah metode yang memadukan antara hiburan dengan pembelajaran. Dengan adanya edutainment juga dapat membuat proses pembelajaran menjadi menyenangkan dan dapat meningkatkan minat peserta didik. Untuk itu, konsep eduitaiment bagus untuk diterapakan.

Manfaat edutainment diantaranya, peserta didik merasa gembira saat pembelajaran, dapat mengendalikan emosi mereka, mengembangkan nalar anak, meningkatkan minat dan motivasi, serta dapat mencapai hasil belajar yang optimal. Perpaduan antara belajar dan hiburan yang menyenangkan ini dapat membantu anak untuk belajar lebih efektif karena diterapkan dalam kondisi yang menyenangkan dan bebas dari tekanan.

Metode bercerita (storytelling) adalah bagian dari cara penyajian pembelajaran yang digunakan oleh pendidik dalam bentuk cerita. Cerita yang diangkat disesuaikan dengan tujuan yang akan dicapai. Dalam pelaksanaan kegiatan pembelajaran di Taman Kanak-Kanak, metode bercerita diperlukan dalam upaya meningkatkan kemampuan guru.

Bercerita juga merupakan cara mentransformasikan nilai-nilai kebaikan. Seorang guru hendaklah mampu menjadi seorang pendongeng yang baik agar materi yang akan disampaikan diterima dan dipahami oleh peserta didik. Cerita yang disajikan pun bernuansa ceria, gembira, lucu, dan mudah dimengerti.

Dari uraian di atas, dapat ditarik simpulan bahwa keberadaan guru-guru di tingkat pendidikan usia dini dituntut untuk dapat memiliki keterampilan berbicara, sehingga dapat menciptakan pembelajaran yang menyenangkan.

\section{METODE PELAKSANAAN}

Pelatihan ini diselenggarakan di TPQ Natiqul Quran yang beralamat di Jalan Al Ihsan RT 02/07, Kamapung Sawah, Kecamatan Ciputat, Tangerang Selatan. Sekolah ini terpilih sebagai tempat pelatihan karena berdasarkan hasil observasi dan survei terhadap guru-guru, informasi yang didapat yaitu para guru di TPQ tersebut jarang mendapatkan 
pelatihan keterampilan berbicara, Selain itu, mereka belum mengetahui metode-metode dalam meningkatkan keterampilan berbicara, seperti metode edutainment dan metode storytelling.

Metode yang digunakan dalam pengabdian masyarakat ini adalah dengan metode ceramah plus yang dipadukan dengan diskusi, tanya-jawab, dan praktik (pelatihan). Metode ceramah digunakan saat pelaksana dan narasumber memberikan materi dan pelatihan terkait dengan metode edutainment dan metode storytelling. Diskusi dan tanya jawab digunakan pada saat para peserta melontarkan pertanyaan yang berkaitan dengan topik, sedangkan praktik (pelatihan) digunakan saat para peserta mempraktikkan atau menerapkan metode yang telah disampaikan.

Alat-alat yang digunakan untuk kegiatan pengabdian kepada masyarakat ini disediakan oleh pihak mitra dan beberapa disediakan oleh pihak tim. Alat- alat yang disediakan oleh pihak mitra adalah proyektor dan laptop. Proyektor digunakan sebagai sarana untuk menyampaikan materi tentang metode-metode peningkatan keterampilan berbicara. Alat-alat yang disediakan oleh tim adalah buku tulis kecil, hand out pelatihan, dan alat tulis pendukung lainnya.

Adapun cara penyajian dan penjelasan alur kegiatan, yaitu: 1) Persiapan, meliputi survei awal, perizinan, penentuan peserta, pembuatan proposal dan penyelesaian administrasi, dan menyiapkan materi pelatihan; 2) Pelaksanaan, meliputi pelaksanaan tahap pertama, kedua, dan ketiga; 3) Evaluasi; 4) Pelaporan.

Ketua dan anggota tim pelaksana abdimas adalah dosen dengan spesifikasi pendidikan. Sinergi tim sebagai dosen yang berlatar belakang Bahasa Indonesia sangat menunjang pencapaian target pelatihan ini. Selain itu, tim abdimas pun melibatkan narasumber yang mumpuni di bidang PAUD dan dua mahasiswa dalam kegiatan tersebut. Adapun sinergi tim tergambar dalam tabel berikut ini.

Tabel 1 Kualifikasi Sinergi Tim Pelaksana

\begin{tabular}{|c|c|c|c|c|}
\hline No & Nama & NIDN/NPM & $\begin{array}{l}\text { Program } \\
\text { Studi }\end{array}$ & Kualifikasi \\
\hline 1. & $\begin{array}{l}\text { Adi Permana, } \\
\text { M.Pd. }\end{array}$ & 0326067901 & $\begin{array}{l}\text { Pendidikan } \\
\text { Bahasa } \\
\text { Indonesia }\end{array}$ & $\begin{array}{l}\text { Ketua pelaksana, } \\
\text { pengampu mata } \\
\text { pendidikan }\end{array}$ \\
\hline 2. & $\begin{array}{l}\text { Hilda Hilaliyah, } \\
\text { M.Pd. }\end{array}$ & 0324118501 & $\begin{array}{l}\text { Pendidikan } \\
\text { Bahasa } \\
\text { Indonesia }\end{array}$ & $\begin{array}{l}\text { Anggota pelaksana, Dosen } \\
\text { pengampu mata kuliah } \\
\text { Pendidikan Bahasa Indonesia }\end{array}$ \\
\hline 3. & Siti Jubei, M.Pd. & 0331126408 & $\begin{array}{l}\text { Pendidikan } \\
\text { Bahasa } \\
\text { Indonesia }\end{array}$ & $\begin{array}{l}\text { Anggota pelaksana, Dosen } \\
\text { pengampu mata kuliah } \\
\text { Pendidikan Bahasa Indonesia }\end{array}$ \\
\hline 4. & Bella Oktaviani & 201621500166 & $\begin{array}{l}\text { Pendidikan } \\
\text { Bahasa } \\
\text { Indonesia }\end{array}$ & $\begin{array}{l}\text { Mahasiswa Semester } \mathrm{V} \text {, } \\
\text { tenaga lapangan }\end{array}$ \\
\hline 5. & $\begin{array}{l}\text { Adhyana } \\
\text { Muzfirah }\end{array}$ & 201621500156 & $\begin{array}{l}\text { Pendidikan } \\
\text { Bahasa } \\
\text { Indonesia }\end{array}$ & $\begin{array}{l}\text { Mahasiswa Semester } \\
\text { tenaga lapangan }\end{array}$ \\
\hline
\end{tabular}


Tabel 2 Kualifikasi Narasumber

\begin{tabular}{|c|c|c|}
\hline No. & Nama & Kualifikasi \\
\hline 1. & Sumarti, M. Pd. & $\begin{array}{l}\text { a. Praktisi Neuroliterasi dan CB Fonik } \\
\text { b. Narasumber Kurikulum PAUD di Kemendikbud } \\
\text { c. Dosen Pendidikan Bahasa Indonesia }\end{array}$ \\
\hline
\end{tabular}

\section{HASIL DAN PEMBAHASAN}

\section{Alur Kegiatan}

Alur kegiatan pengabdian kepada masyarakat ini adalah sebagai berikut:

1. Persiapan

Pada tahapan ini, kegiatan-kegiatan yang dilakukan, adalah:

a. Survei awal tempat pelaksanaan: Survei awal ini dilakukan dengan cara mewawancarai pimpinan yayasan dan Kepala Taman Pendidikan Quran (TPQ) terkait dengan sumber daya manusia (pengajar) di tempat tersebut.

b. Perizinan: Kegiatan ini dilakukan untuk memperoleh perizinan sekaligus menentukan waktu pelaksanaan dan hal-hal yang berkaitan dengan kegiatan pengabdian kepada masyarakat.Perizinan ini didapatkan berupa keluarnya surat kesediaan mitra yang diberikan kepada tim pelaksana.

c. Penentuan Peserta: Penentuan peserta ini dilakukan agar adanya kejelasan terkait peserta yang akan mengikuti kegiatan ini.

d. Pembuatan Proposal dan Penyelesaian Administrasi: Pada tahapan ini, tim pelaksana menyiapkan proposal kegiatan yang diserahkan kepada pihak Lembaga Penelitian dan Pengabdian kepada Masyarakat (LPPM) guna memperoleh surat tugas pelaksanaan pengabdian kepada masyarakat.

e. Menyiapkan Materi Pelatihan: Pada tahapan ini, tim pelaksana menyiapkan materi pelatihan terkait dengan hal-hal yang disampaikan pada kegiatan pengabdian kepada masyarakat.

2. Pelaksanaan

Kegiatan pengabdian kepada masyarakat ini dilaksanakan dengan beberapa tahapan, yaitu:

a. Pelaksanaan Pertama, Minggu, 11 November 2018: Pada pelaksanaan pertama ini, tim pelaksana melakukan perkenalan dengan para peserta, yaitu guru-guru TPQ yang mengajar di tempat tersebut. Dari kegiatan ini, tim pelaksana mendapatkan informasi terkait dengan minimnya pengetahuan mereka tentang metode pembelajaran yang aktif, kreatif, dan menyenangkan.

b. Pelaksanaan Kedua, Minggu, 18 November 2018: Pada pelaksanaan kedua ini, tim abdimas melakukan penyampaian materi yang berkaitan dengan metode edutainment dan metode storytelling, sehingga para peserta mendapatkan wawasan baru terkait dengan metode-metode tersebut yang dapat dimanfaatkan saat menghadapi para peserta didik di TPQ.

c. Pelaksanaan Ketiga, Minggu, 25 November 2018: Pada pelaksanaan ketiga ini, tim abdimas melakukan pelatihan cara menerapkan metode edutainment dan metode storytelling. Para peserta diambil secara random untuk mengaplikasikan metode-metode tersebut dengan materi yang berbeda-beda.

3. Evaluasi

Evaluasi bertujuan untuk melihat perkembangan program yang dilaksanakan berjalan lancar atau tidak. Tim abdimas mengumpulkan hasil kuesioner yang telah 
diisi oleh para peserta. Kuesioner tersebut berupa evaluasi narasumber, pelaksanaan, penerapan (pengaplikasian), dan masukan-masukan terkait dengan kegiatan pengabdian kepada masyarakat.

4. Pelaporan

Laporan dibuat sebagai bentuk pertanggungjawaban tim terhadap kegiatan yang dilaksanakan. Laporan tersebut berupa laporan monitoring dan evaluasi (monev) yang dilaksanakan oleh LPPM dan pengumpulan laporan akhir beserta logbook dan keuangan.

Berdasarkan hasil kegiatan pengabdian kepada masyarakat yang telah dilakukan, tampak antusias para peserta, yaitu guru-guru TPQ, terhadap tahapan yang dilalui. Pada saat penyampaian materi, para peserta aktif bertanya terkait dengan materi yang disampaikan. Hal ini menjadi indikator yang positif bahwasanya kegiatan seperti ini sangatlah dibutuhkan untuk menambah pengetahuan dan meningkatkan kemampuan berbicara peserta pada saat proses belajar-mengajar di kelas.

Pentingnya kemampuan berbicara dalam kehidupan manusia mungkin diperlukan suatu kegiatan ataupun pembelajaran yang berfungsi untuk mengasah kemampuan berbicara manusia (Armani dkk., 2014), misalnya dengan metode edutainment dan storytelling. Hamid (dalam Khusnasani dkk., 2017) menyatakan bahwa edutainment adalah suatu cara untuk membuat proses pendidikan dan pengajaran dapat menjadi begitu menyenangkan, sehingga para siswa dapat dengan mudah menangkap esensi dari pembelajaran tanpa merasa bahwa mereka sedang belajar. Melalui metode edutainment proses belajar mengajar dikemas dengan baik agar tidak menjadi sebuah proses yang membosankan atau bahkan menyengsarakan para siswa. Metode ini adalah metode yang mendesain kegiatan belajar mengajar, sehingga begitu menghibur dan menjadikan siswa kreatif dan nyaman di kelas. Dengan metode ini guru diharapkan akan mampu menciptakan interaksi yang baik dengan siswanya, sehingga mereka akan merasa dihargai dan dilibatkan saat pembelajaran berlangsung. (Sianturi, 2014).

Teori belajar berbasis edutainment merupakan serangkaian teori yang mengungkapkan bagaimana melakukan kegiatan pembelajaran yang menyenangkan dan tidak membosankan bagi peserta didik. Artinya, teori-teori ini lebih menekankan pada pelaksanaan pembelajaran yang melibatkan peran aktif peserta didik dan guru hanya sebatas sebagai fasilitator bagi terlaksananya kegiatan pembelajaran tersebut. (Fadlillah, M., dkk., 2014)

Pengertian storytelling diungkapkan pula oleh Samantaray (dalam Khusnasani dkk., 2017), yang menyatakan bahwa : "Storytelling the art of narrating a tale from memory rather than reading is one of the oldest of all art forms. Storytelling is the original form of teaching and has the potential of fostering emotional intelligence and helps the child gain insight into human behavior. Moreover, storytelling can provide a motivating and low anxiety context for language lear-ning." Pendapat Samantaray tersebut dapat diartikan bahwa storytelling adalah seni menceritakan sebuah cerita lebih dari sekadar membacakan cerita. Storytelling atau bercerita adalah bentuk asli dari pengajaran dan memiliki potensi untuk membina kecerdasan emosional dan membantu anak memperoleh wawasan tentang perilaku manusia. Storytelling dapat meningkatkan motivasi siswa dan mengurangi kebosanan dalam pembelajaran bahasa.

Adapun tahapan-tahapan untuk meningkatkan keterampilan berbicara para peserta dengan menerapkan metode edutainment dan storytelling adalah sebagai berikut : 
1. Guru mematangkan langkah-langkah pembelajaran dengan menerapkan metode edutainment berbasis storytelling;

2. Guru lebih berlatih dalam menyajikan materi dengan memberikan contoh pelafalan yang jelas dengan bahasa yang baik dan komunikatif untuk menciptakan suasana ceria;

3. Guru menggunakan media yang lebih konkret agar lebih menarik perhatian siswa, misalnya dalam hal ini digunakan media boneka tangan dan pemakaian kostum untuk memperkuat karakter tokoh dalam cerita;

4. Guru lebih menghidupkan penyajian dongeng dan mengajak siswa ikut berinteraksi dengan penyaji dongeng;

5. Guru melaksanakan games, misalnya permainan pesan berantai dalam langkah pembelajaran tujuannya adalah untuk mendukung kegiatan proses menyimak siswa dengan prinsip edutainment.

\section{Luaran yang Dicapai} adalah:

Adapun luaran yang dicapai dalam kegiatan pengabdian kepada masyarakat ini

1. Para peserta (guru) mampu menerapkan keterampilan berbicara dengan metode edutainment dan metode bercerita (storytelling) saat pembelajaran di kelas, sehingga kreativitas dan kompetensi diri guru dapat meningkat.

2. Luaran yang dihasilkan dari pelaksanaan pelatihan ini adalah artikel. Artikel ilmiah hasil pengabdian kepada masyarakat yang akan dipublikasikan pada Jurnal Pengabdian kepada Masyarakat (PkM) Universitas Indraprasta PGRI.

\section{SIMPULAN}

Simpulan dari kegiatan pengabdian kepada masyarakat adalah sebagai berikut:

1. Metode edutainment dan storytelling adalah suatu metode pembelajaran yang dikemas dengan baik yang akan mampu mengatasi kebosanan siswa dalam proses belajar.

2. Edutainment dan storytelling adalah suatu proses metode yang didesain sedemikian rupa sehingga muatan pendidikan dan hiburan dapat dikombinasikan secara harmonis sehingga pembelajaran terasa menyenangkan.

\section{DAFTAR PUSTAKA}

Armani, Marli, S., Kartono. (2014) Metode Edutainment untuk Meningkatkan Kemampuan Berbicara pada Siswa di Sekolah Dasar. Jurnal Pendidikan dan $\begin{array}{llllll}\text { Pembelajaran } & \text { Vol. } & 03 & \text { No. } & 07 & \text { (2014). }\end{array}$ http://jurnal.untan.ac.id/index.php/jpdpb/article/view/6265/pdf

Fadlillah, M., dkk. (2014). Edutainment Pendidikan Anak Usia Dini. Jakarta: Kencana Prenadimedia Group.

Khusnasani, I., Winarni, R., Riyadi. (2017). Penerapan Metode Edutainment Berbasis Storytelling untuk Meningkatkan Keterampilan Menyimak Dongeng pada Siswa Sekolah Dasar. Jurnal Didaktika Dwija Indria (2017) Vol. 05 No.04 2017 http://jurnal.fkip.uns.ac.id/index.php/pgsdsolo/article/view/10411 
Sianturi, R. A. (2014) Penerapan Metode Edutainment dalam Pembelajaran Menulis Teks Berita. Bahtera Bahasa: Antologi Pendidikan Bahasa dan Sastra Indonesia. No. 2, Desember 2014. http://ejournal.upi.edu/index.php/PSPBSI/issue/view/65 